\title{
Commentary
}

\section{Enhancing Periodontal Health Through Regenerative Approaches}

\author{
William V. Giannobile* ${ }^{\star \dagger}$ and Pamela K. McClain ${ }^{\ddagger}$
}

$\mathrm{P}$ reservation of the natural dentition in a state of health has long been a goal in dentistry and periodontics. Recent research suggests that almost $50 \%$ of the U.S. population aged $>30$ years and $70 \%$ of those aged $>65$ years suffer from periodontal breakdown. ${ }^{1}$ Even more compelling is the evidence that $38 \%$ of the population exhibit moderate to severe periodontitis. Because most individuals prefer maintaining their teeth and abhor the thought of dentures or other replacements, it is imperative that periodontal disease be managed early and appropriately. However, when patients present with moderate to severe disease, research suggests that tooth retention and maintenance in health is achievable with a variety of approaches, including regenerative therapy. Periodontists are the trained experts in the field of hard and soft tissue regeneration around teeth and in providing periodontal therapy for all levels of disease. However, if extraction is required, the periodontist is also qualified to replace teeth with implants and is best qualified to maintain implants and reduce or manage complications associated with implants, which have also increased. ${ }^{2}$ As a result, it is critical that periodontists, as the premier providers of periodontal care, establish the potential of regeneration of the hard and soft tissues when feasible to maintain the natural dentition in lieu of replacement therapy.

This is truly an exciting time in regenerative biology as opportunities are expanded for innovations in restoring tissues lost as a result of periodontal diseases. Periodontics has a long history of reconstructive approaches to improve tooth support, enhance esthetics, and maintain periodontal health. ${ }^{3}$ Since the last American Academy of Periodontology (AAP) Consensus Workshop on the topic of regeneration held in 2003, there have been significant advance-

\section{KEY WORDS}

Bone transplantation; guided tissue regeneration, periodontal; periodontal diseases; tissue engineering; wound repair.

* Department of Periodontics and Oral Medicine, University of Michigan School of Dentistry, Ann Arbor, MI.

$\dagger$ Department of Biomedical Engineering, College of Engineering, University of Michigan, Ann Arbor, MI.

‡ Private practice, Aurora, CO. ments in both preclinical development and the clinical arena. New regenerative technologies for repairing periodontal soft $^{4}$ and hard tissues for intrabony, dehiscence, ${ }^{5}$ and furcation defects ${ }^{6}$ have grown rapidly during this period. Such approaches include optimization of biomaterials, biologic factors, and the introduction of novel cell delivery systems. ${ }^{7}$ In this supplement to the Journal of Periodontology, current evidence is provided on clinical therapies designed to regenerate periodontal soft and hard tissues around teeth to promote tooth retention. ${ }^{8}$ The assembly of timely systematic reviews and consensus reports published in this issue of the Journal of Periodontology provides an opportunity to support the mission of the AAP "to provide members the expertise and resources to enhance the evaluation and diagnosis of oral conditions, assessment of risk for future disease, and delivery of specialty periodontal non-surgical, surgical, and medical care for our patients." One of the pillars of this mission is the strong commitment by the AAP to the promotion of science and evidence-based care for practitioners delivering care to the public.

The purpose of the AAP Workshop held June 1 to 4, 2014 in Chicago, Illinois, entitled Enhancing Periodontal Health Through Regenerative Approaches was to advance the understanding and implementation of periodontal regenerative medicine. The state-of-the-science conference summarized the existing literature in the field, evaluated clinical applications of the science, and identified priorities for future research in periodontology. This issue of the Journal of Periodontology highlights those systematic reviews on periodontal soft tissue root coverage procedures, ${ }^{9}$ gingival enhancement or replacement for non-root coverage procedures, ${ }^{10}$ regeneration of periodontal intrabony ${ }^{11}$ and furcation defects, ${ }^{12}$ and emerging technologies in periodontal regeneration. ${ }^{13}$ Corresponding to these systematic reviews are consensus reports focusing on the current evidence supporting the reconstruction of lost periodontal hard and soft tissues for regeneration. Concepts that emerged in the consensus included future areas of research, such as the use of minimally invasive surgical ${ }^{14}$ and diagnostic ${ }^{15}$ procedures, as

doi: 10.1902/jop.2015.140525 
Table I.

\section{AAP Workshop on Enhancing Periodontal Health Through Regenerative Approaches: Focus Areas for Systematic Reviews and Consensus Reports}

\begin{tabular}{|c|c|}
\hline Focus Area & Contributors \\
\hline AAP Workshop on Periodontal Regeneration & $\begin{array}{l}\text { Organizing committee: William V. Giannobile (co-chair), Pamela K. } \\
\text { McClain (co-chair), Kenneth S. Kornman (JOP Editor-in-Chief), } \\
\text { Laurie K. McCauley, Michael K. McGuire, Myron Nevins, John C. } \\
\text { Gunsolley (consultant), Marita R. Inglehart (consultant), Mariano } \\
\text { Sanz (consultant) }\end{array}$ \\
\hline \multicolumn{2}{|l|}{ Periodontal Soft Tissue Approaches } \\
\hline Periodontal Soft Tissue Root Coverage Procedures & $\begin{array}{l}\text { Workshop members: Dimitris N. Tatakis (chair), Leandro } \\
\text { Chambrone (reviewer), Edward P. Allen, Burton Langer, } \\
\text { Christopher R. Richardson, lon Zabalegui, Homayoun H. Zadeh }\end{array}$ \\
\hline Periodontal Soft Tissue Non-Root Coverage Procedures & $\begin{array}{l}\text { Workshop members: E. Todd Scheyer (chair), David M. Kim } \\
\text { (reviewer), Rodrigo Neiva (reviewer), Serge Dibart, Henry } \\
\text { Greenwell, Vanchit John, Laureen Langer, Giulio Rasperini }\end{array}$ \\
\hline \multicolumn{2}{|l|}{ Periodontal Hard Tissue Defects } \\
\hline Periodontal Regeneration: Intrabony Defects & $\begin{array}{l}\text { Workshop members: Mark A. Reynolds (chair), Richard T. Kao } \\
\text { (reviewer), Salvador Nares (reviewer), Paulo M. Camargo, Jack } \\
\text { G. Caton, Donald S. Clem, Joseph P. Fiorellini, Maria L. Geisinger, } \\
\text { Michael P. Mills, Marc L. Nevins }\end{array}$ \\
\hline Periodontal Regeneration: Furcation Defects & $\begin{array}{l}\text { Workshop members: Michael S. Reddy (chair), Gustavo Avila-Ortiz } \\
\text { (reviewer), Mary E. Aichelmann-Reidy, Perry R. Klokkevold, Kevin } \\
\text { G. Murphy, Paul S. Rosen, Robert G. Schallhorn, Anton Sculean, } \\
\text { Hom-Lay Wang }\end{array}$ \\
\hline Emerging Regenerative Approaches for Periodontal Reconstruction & $\begin{array}{l}\text { Workshop members: David L. Cochran (chair), Hector F. Rios } \\
\text { (reviewer), Zhao Lin (reviewer), Jill D. Bashutski, Yong-Hee } \\
\text { Patricia Chun, Charles M. Cobb, George A. Mandelaris, Bradley } \\
\text { S. McAllister, Shinya Murakami, Martha J. Somerman }\end{array}$ \\
\hline
\end{tabular}

well as the consideration of patient-reported outcomes ${ }^{16}$ for periodontal reconstructive technologies.

\section{WORIKSHOP OBJECTIVES}

The workshop objectives included the following: 1) provide a venue for periodontal clinicians and scientists to assess the state of knowledge of periodontal regenerative technologies; 2) develop consensus reports based on systematic reviews including priorities for future research and identify the best evidence available to manage different clinical scenarios; and 3) evaluate the range of clinical applications and expected outcomes to patient care based on the current science for publication in Clinical Advances in Periodontics.

The workshop contributors of the systematic reviews, consensus reports, and practical applications are shown in Table 1. The approach of this first-of-its kind workshop sought to provide practical clinical translation of current evidence. This AAP workshop model contrasts with other published systematic reviews from evidencebased workshops that only include systematic reviews and consensus summaries that are often challenging to translate into clinical practice. This workshop provides clear summaries of evidence and multiple approaches to clinical translation through scenario-based interpretations of the systematic reviews and dynamic digital approaches to clinical translation in the Practical Applications section of an upcoming issue of Clinical Advances in Periodontics.

The authors believe that it is critically important for the AAP to lead the profession of periodontology in the current and emerging science for advancing the optimal care of patients. Further, they hope that the readership will appreciate this assembly of cutting-edge advances in the field that was provided by dedicated clinicians, academicians, researchers, and innovators in the field who were a part of this conference. Their tremendous dedication, insights, and expertise have resulted in what is believed will be a valuable product for periodontists for years to come. It is hoped that this workshop will also serve as an inspiration to appreciate the advances that have been made, while also recognizing there is significant distance to travel to further promote the practice of periodontics for the betterment of our patient's oral health and overall well-being. 


\section{ACKNOWLEDGMENTS}

The American Academy of Periodontology Regeneration Workshop was supported in part by the American Academy of Periodontology Foundation, Geistlich Pharma North America, Colgate-Palmolive, and the Osteology Foundation. The authors thank the following members of the workshop organizing committee: Kenneth Kornman, Laurie McCauley, Michael McGuire, Myron Nevins, and Mariano Sanz (European Federation of Periodontology representative and consultant). The authors also appreciate the outstanding AAP staff support of Stephanie Heffner, Erin O'Donnell Dotzler, Meg Dempsey, Julie Daw, Lia Hudson, and Bethanne Wilson. The authors report no conflicts of interest related to this publication.

\section{REFERENCES}

1. Eke PI, Dye BA, Wei L, Thornton-Evans GO, Genco RJ; CDC Periodontal Disease Surveillance workgroup. Prevalence of periodontitis in adults in the United States: 2009 and 2010. J Dent Res 2012;91:914-920.

2. [no authors listed]. Peri-implant mucositis and periimplantitis: a current understanding of their diagnoses and clinical implications. J Periodontol 2013;84:436-443.

3. Giannobile WV. Treatment of periodontitis: Destroyed periodontal tissues can be regenerated under certain conditions. J Periodontol 2014;85:1151-1154.

4. Sanz M, Simion M; Working Group 3 of the European Workshop on Periodontology. Surgical techniques on periodontal plastic surgery and soft tissue regeneration: Consensus report of Group 3 of the 10th European Workshop on Periodontology. J Clin Periodontol 2014; 41(Suppl. 15):S92-S97.

5. McGuire MK, Scheyer ET. Xenogeneic collagen matrix with coronally advanced flap compared to connective tissue with coronally advanced flap for the treatment of dehiscence-type recession defects. $J$ Periodontol 2010;81:1108-1117.

6. Susin C, Wikesjö UM. Regenerative periodontal therapy: 30 years of lessons learned and unlearned. Periodontol $20002013 ; 62: 232-242$.
7. Kim JH, Park CH, Perez RA, et al. Advanced biomatrix designs for regenerative therapy of periodontal tissues [published online ahead of print August 19, 2014]. J Dent Res. doi:10.1177/0022034514540682.

8. Wang HL, Greenwell H, Fiorellini J, et al; Research, Science and Therapy Committee. Periodontal regeneration. J Periodontol 2005;76:1601-1622.

9. Chambrone L, Tatakis DN. Periodontal soft tissue root coverage procedures: A systematic review from the AAP regeneration workshop. J Periodontol 2015;86 (Suppl.):S8-S51.

10. Kim DM, Neiva R. Periodontal soft tissue non-root coverage procedures: A systematic review from the AAP regeneration workshop. J Periodontol 2015;86(Suppl.): S56-S72.

11. Kao RT, Nares S, Reynolds MA. Periodontal regeneration Intrabony defects: A systematic review from the AAP regeneration workshop. J Periodontol 2015;86(Suppl.): S77-S104.

12. Avila-Ortiz G, De Buitrago JG, Reddy MS. Periodontal regeneration - Furcation defects: A systematic review from the AAP regeneration workshop. J Periodontol 2015;86(Suppl.):S108-S130.

13. Lin Z, Rios HF, Cochran DL. Emerging regenerative approaches for periodontal reconstruction: A systematic review from the AAP regeneration workshop. J Periodontol 2015;86(Suppl.):S134-S152.

14. Cortellini P. Minimally invasive surgical techniques in periodontal regeneration. J Evid Based Dent Pract 2012; 12(Suppl. 3):89-100.

15. Xiang X, Sowa MG, lacopino AM, et al. An update on novel non-invasive approaches for periodontal diagnosis. J Periodontol 2010;81:186-198.

16. McGuire MK, Scheyer ET, Gwaltney C. Commentary: Incorporating patient-reported outcomes in periodontal clinical trials. J Periodontol 2014;85:1313-1319.

Correspondence: Dr. William V. Giannobile, Department of Periodontics and Oral Medicine, University of Michigan School of Dentistry, 1011 N. University Ave., Ann Arbor, MI 48109-1078. E-mail: william.giannobile@umich.edu.

Submitted September 15, 2014; accepted for publication September 29, 2014. 